\title{
DIAGONALISASI BENTUK KUADRATIK IRISAN KERUCUT
}

\author{
Yusmet Rizal \\ Jurusan Matematika FMIPA Universitas Negeri Padang \\ e-mail : yusmet_abdurrahman@yahoo.co.id \\ DOI : 10.24036/eksakta/vol19-iss01/132
}

\begin{abstract}
In general, the conic section equation consists of three parts, namely quadratic, cross-product, and linear terms. A conic sections will be easily determined by its shape if it does not contain cross-product term, otherwise it is difficult to determine. Analytically a cone slice is a quadratic form of equation. A concept in linear algebraic discussion can be applied to facilitate the discovery of a shape of a conic section. The process of diagonalization can transform a quadratic form into another form which does not contain crosslinking tribes, ie by diagonalizing the quadrate portion. Hence this paper presents the application of an algebraic concept to find a form of conic sections.
\end{abstract}

Keywords $\quad$ : conic section (conic), transformation, quadratic, diagonalization.

\section{PENDAHULUAN}

Pada bagian ini disajikan dua konsep dasar, yaitu irisan kerucut dan proses diagonalisasi matriks. Beberapa engertian dan sifat dasar akan disajikan di sini. Melalui kajian terhadap terhadap konsep dasar ini dirancang suatu cara untuk menyelesaikan permasalahan yang diajukan.

\section{A. Irisan Kerucut}

Dalam geometri irisan kerucut, suatu kerucut dapat dipandang sebagai bangun geometri yang mempunyai dua bagian, yang meluas ketakberhingga dalam dua arah. Pembahasan pada tulisan ini dibatasi pada kerucut lingkaran tegak. Sebagian kerucut lingkaran tegak yang terdiri atas dua bagian dapat dilihat pada gambar berikut.

Suatu pembangkit disebut juga elemen dari kerucut, yaitu garis yang terletak pada kerucut, dan semua pembangkit suatu kerucut melalui titik $V$ yang dinamakan puncak.
Suatu irisan kerucut adalah kurva perpotongan antara suatu bidang dengan kerucut lingkaran tegak. Terdapat lima jenis kurva yang terjadi dari irisan tersebut, yaitu garis, lingkaran, parabol, ellips, dan hiperbol seperti terlihat pada Gambar 2 berikut:

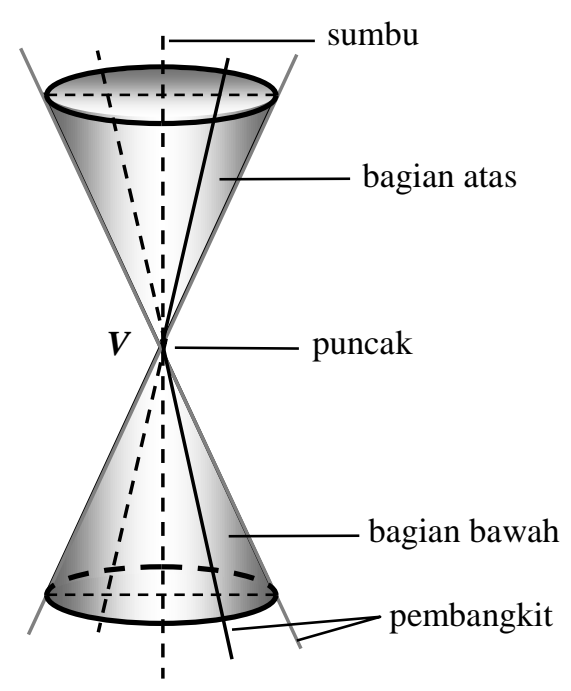

Gambar 1 

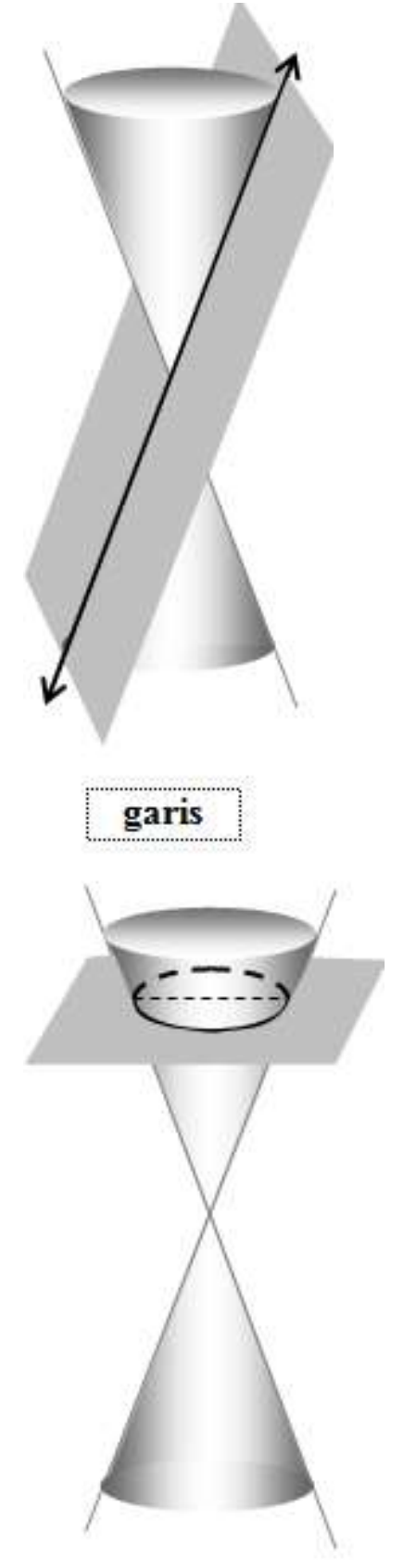

\section{lingkaran}

Gambar 2

Garis terjadi jika bidang pemotong memuat tepat satu pembangkit. Dalam hal ini bidang pemotong juga melalui puncak kerucut. Lingkaran terjadi jika bidang pemotong tegaklurus dengan sumbu kerucut.
Parabol terjadi jika bidang pemotong sejajar dengan tepat satu pembangkit. Ellips terjadi jika bidang pemotong tidak sejajar dengan pembangkit manapun, atau bidang pemotong memotong semua pembangkit. Hiperbol terjadi jika bidang pemotong sejajar dengan dua pembangkit, sehingga bidang pemotong akan memotong kedua bagian kerucut.
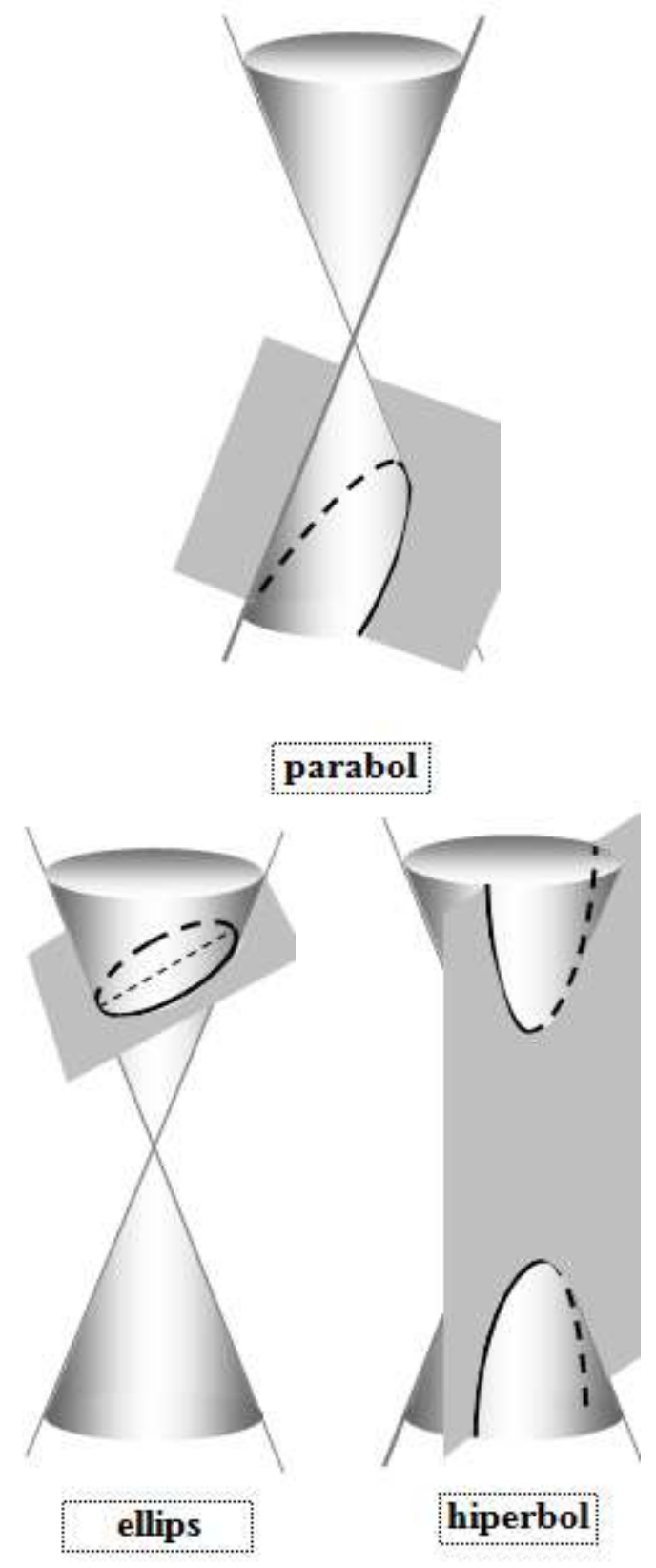

Gambar 3

Suatu titik juga dapat dinyatakan sebagai suatu irisan kerucut, yaitu jika bidang 
melalui titik puncak memotong kerucut secara horizontal.

Secara analitik suatu irisan kerucut dapat disajikan dengan bentuk persamaan berikut, yang disebut juga bentuk umum persamaan irisan kerucut. $a x^{2}+2 b x y+c y^{2}+d x+e y+f=0 \ldots($ 1)

Persamaan di atas secara aljabar dapat dimanipulasi menjadi persamaan bentuk matriks berikut:

$$
\left[\begin{array}{ll}
x & y
\end{array}\right]\left[\begin{array}{ll}
a & b \\
b & c
\end{array}\right]\left[\begin{array}{l}
x \\
y
\end{array}\right]+\left[\begin{array}{ll}
d & e
\end{array}\right]\left[\begin{array}{l}
x \\
y
\end{array}\right]+f=0
$$

atau dapat dinyatakan sebagai

$$
\begin{aligned}
& \mathbf{x}^{\mathrm{T}} A \mathbf{x}+B \mathbf{x}+f= \\
& 0, \cdots \cdots \cdots \cdots(2)
\end{aligned}
$$

dimana

$$
\mathrm{x}=\left[\begin{array}{l}
x \\
y
\end{array}\right], A=\left[\begin{array}{ll}
a & b \\
b & c
\end{array}\right], B=\left[\begin{array}{ll}
d & e
\end{array}\right] .
$$

Suku $\mathbf{x}^{\mathrm{T}} A \mathbf{x}$ disebut juga bentuk kuadratik yang diasosiasikan. Dalam bentuk ini kita selalu dapat memilih matriks $A$ sebagai matriks simetris, meskipun terdapat kemungkinan lain.

Pembahasan berikutnya akan disajikan suatu sifat yang dapat mentransformasikan suatu bentuk kuadratik yang memuat suku hasilkali silang menjadi bentuk yang tidak memuat suku hasilkali silang.

\section{B. Diagonalisasi Bentuk Kuadratik}

Misalkan $\mathbf{x}^{\mathrm{T}} A \mathbf{x}$ suatu bentuk kuadratik yang diasosiasikan dari suatu persamaan irisan kerucut dengan memilih $A$ sebagai matriks simetris. Bagian ini akan diperlihatkan bahwa, jika $P$ suatu matriks ortogonal, maka perubahan variabel

$$
\mathbf{x}=P \mathbf{y}
$$

akan mengkonversikan bentuk kuadratik $\mathbf{x}^{\mathrm{T}} A \mathbf{x}$ menjadi

$$
\begin{aligned}
& (P \mathbf{y})^{\mathrm{T}} A(P \mathbf{y})=\quad \mathbf{y}^{\mathrm{T}}\left(P \quad{ }^{\mathrm{T}} A P\right) \mathbf{y} \\
& \cdots \cdots \cdot \cdots(3)
\end{aligned}
$$

Karena kita memilih $A$ matriks simetris maka matriks $P{ }^{\mathrm{T}} A P$ juga simetris, sehingga persamaan (3) adalah sebuah bentuk kuadratik baru dalam variabelvariabel $\mathbf{y}$. Pemilihan matriks $P$ pada proses ini sangat menentukan agar bentuk kuadratik yang baru tidak memiliki hasilkali silang. Sifat-sifat berikut menyajikan suatu cara pemilihan matriks $P$.

\section{Teorema 1}

Jika A adalah matriks simetris berukuran $n \times n$ dengan nilai-nilai eigennya $\lambda_{1}$, $\lambda_{2}, \ldots, \lambda_{n}$ dalam urutan menurun dengan $\mathbf{x}$ dibatasi

$\|\mathbf{x}\|=1$ relatif terhadap perkalian dalam Euclid di $R^{n}$, maka

$$
\text { a. } \lambda_{1} \geq \mathbf{x}^{\mathrm{T}} A \mathbf{x} \geq \lambda_{n}
$$

b. $\mathbf{x}^{\mathrm{T}} A \mathbf{x}=\lambda_{n}$ jika $\mathbf{x}$ adalah vektor eigen dari $A$ yang sesuai dengan nilai eigen $\lambda_{n}$.

\section{Teorema 2}

Jika $A$ adalah matriks berukuran $n \times n$, maka pernyataan berikut ekivalen :
a. A terdiagonalkan secara ortogonal,
b. A mempunyai suatu himpunan ortonormal dari $n$ vektor eigen.
c. A simetris.

\section{Teorema 3}

Jika A adalah matriks simetris berukuran $n \times n$, maka :
a. semua nilai eigen dari $A$ adalah bilangan riil.
b. vektor-vektor eigen dari ruang eigen yang berbeda adalah ortogonal.

Melalui sifat-sifat ini kita dapat menyusun langkah-langkah untuk 
mendiagonalkan matriks simetris $A$, yaitu

1. Temukan basis untuk setiap ruang eigen dari $A$

2. Terapkan proses Gram-Schmidt terhadap vektor-vektor basis pada ruang hasilkali dalam Euclid, sehingga diperoleh suatu basis ortonormal.

3. Bentuk matriks $P$ dengan kolomkolomnya adalah vektor-vektor pada basis yang diperoleh pada langkah 2. Matriks ini akan mendiagonalkan $A$ secara ortogonal.

\section{Teorema 4}

Misalkan $\mathbf{x}^{\mathrm{T}} A \mathbf{x}$ adalah bentuk kuadratik dalam variabel-variabel di $\mathbf{x}$, dimana $A$ adalah matriks simetris. Jika $P$ mendiagonalisasi $A$ secara ortogonal, dan $\mathbf{x}=P \mathbf{y}$, maka diperoleh bentuk kuadratik

$$
\mathbf{y}^{\mathrm{T}} D \mathbf{y},
$$

dengan $D$ adalah matriks diagonal dengan entri-entri diagonal utamanya adalah nilai eigen yang sesuai.

Bentuk pada persamaan (4) diatas tidak memiliki suku-suku hasilkali silang. Dengan demikian, jika diterapkan pada bentuk kuadratik yang diasosiasikan pada suatu persamaan irisan kerucut maka persamaan (4) merupakan bentuk kuadratik yang diasosiasikan pada suatu bentuk kanonik (standar) irisan kerucut.

Berikut bentuk-bentuk kanonik masing-masing irisan kerucut:

1. Ellips atau lingkaran

$$
\frac{x^{2}}{a^{2}}+\frac{y^{2}}{b^{2}}=1 ; a, b>0
$$
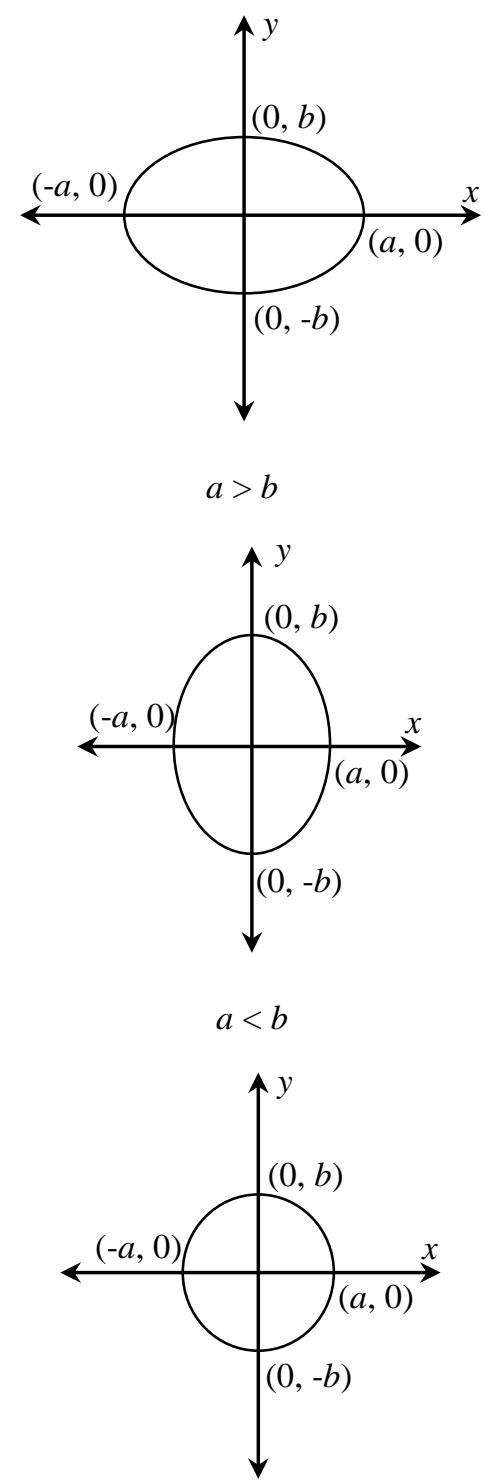

$$
a=b
$$

\section{Hiperbola}

$\frac{x^{2}}{a^{2}}-\frac{y^{2}}{b^{2}}=1$, atau $\frac{y^{2}}{a^{2}}-\frac{x^{2}}{b^{2}}=1 ; a, b>$ 0

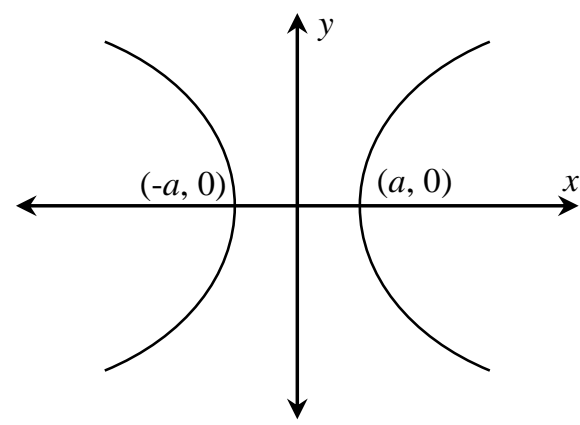




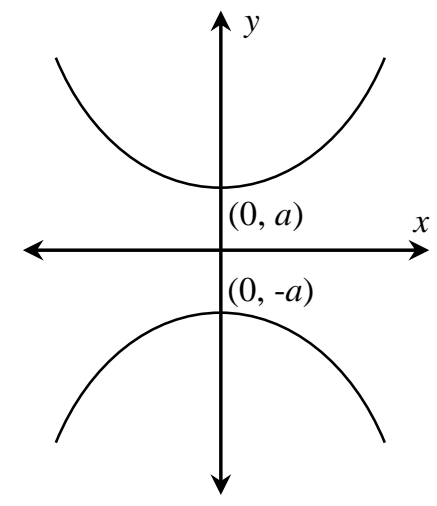

3. Parabola

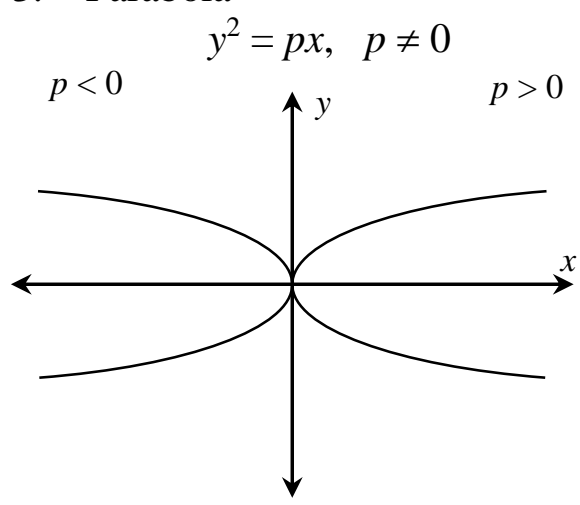

$$
x^{2}=p y, \quad p \neq 0
$$

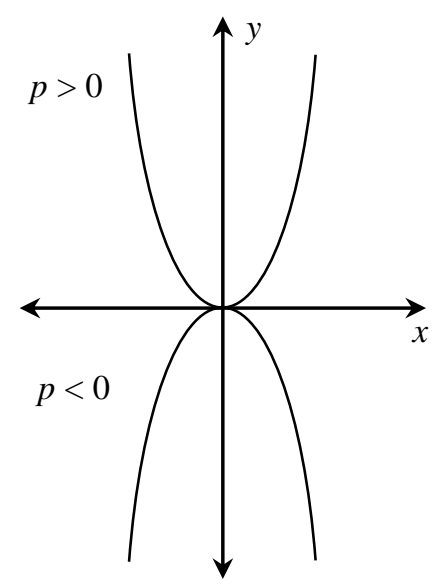

Gambar 4

Jadi, dengan menerapkan proses diagonalisasi pada bentuk kuadratik suatu irisan kerucut tertentu, maka akan diperoleh salah satu dari bentuk standar di atas. Dengan demikian kita dapat menggambarkan dengan mudah irisan kerucut tersebut.

\section{METODE PENELITIAN}

Penelitian ini dimulai dari hasil studi pustaka dengan mempelajari beberapa karya ilmiah yang disajikan dalam bentuk jurnal, bulletin ataupun buku. Dari datadata atau konsep yang telah dikumpulkan, dilakukan proses analisis dengan cara menghubungkan satu atau beberapa konsep dengan kaidah matematika yang benar. Kemudian merumuskan suatu konsep yang diperoleh dari hasil hubungan tersebut. Sehingga diperoleh hasil berupa langkah-langkah untuk mendiagonalisasi bagian kuadratik dari suatu persamaan irisan kerucut, sehingga diperoleh persamaan irisan kerucut yang bebas dari suku hasilkali silang. Akibatnya bentuk irisan kerucut dengan mudah dapat digambarkan.

\section{HASIL DAN PEMBAHASAN}

Misalkan persamaan hentuk matriks irisan kerucut berikut $\quad p$

$$
\begin{aligned}
& \text { dimana } \\
& \mathbf{x}=\left[\begin{array}{l}
x \\
y
\end{array}\right], \quad A=\left[\begin{array}{ll}
a & b \\
b & c
\end{array}\right], \quad B=\left[\begin{array}{ll}
d & e
\end{array}\right] .
\end{aligned}
$$$$
(5)
$$

Persamaan di atas menunjukkan bahwa irisan kerucut tersebut berada dalam bidang koordinat $x y$. Kita akan mentransformasikan sumbu $x y$, sehingga masing-masing sumbu dari irisan kerucut sejajar dengan sumbu-sumbu koordinat yang baru. Ini dapat diperoleh dengan merotasikan sumbu/koprdinat xy menjadi sumbu koordinar $x^{\prime} y^{\prime}, \quad x_{\text {sehingga }}$ persamaan irisan kerucut yang berada pada sistem koordinat $x^{\prime} y^{\prime}$ tidak mengandung suku hasilkali silang. 
Berikut uraian dari langkah-langkah yang dilakukan.

\section{Langkah 1:}

Cari sebuah matriks

$$
P=\left[\begin{array}{ll}
p_{11} & p_{12} \\
p_{21} & p_{22}
\end{array}\right]
$$

yang secara ortogonal mendiagonalisasi A.

\section{Langkah 2:}

Pertukarkan kolom-kolom dari $P$, jika diperlukan untuk menjadikan $\operatorname{det}(P)=1$ untuk menjamin bahwa transformasi koordinat ortogonal

$$
\mathbf{x}=P \mathbf{x}^{\prime},
$$

yaitu

$$
\left[\begin{array}{l}
x \\
y
\end{array}\right]=P\left[\begin{array}{l}
x^{\prime} \\
y^{\prime}
\end{array}\right] \ldots \ldots \ldots \ldots \ldots . . . .
$$

adalah suatu rotasi.

\section{Langkah 3:}

Untuk mendapatkan persamaan irisan kerucut di dalam sistem $x^{\prime} y^{\prime}$ substitusikan (6) ke dalam (5). Hal ini menghasilkan

$$
\left(P \mathbf{x}^{\prime}\right)^{\mathrm{T}} A\left(P \mathbf{x}^{\prime}\right)+B\left(P \mathbf{x}^{\prime}\right)+f=0
$$

atau

$\left(\mathbf{x}^{\prime}\right)^{\mathrm{T}}\left(P^{\mathrm{T}} A P\right) \mathbf{x}^{\prime}+(B P) \mathbf{x}^{\prime}+f=0 . \cdots$ (7)

Karena $P \quad$ secara ortogonal mendiagonalisasi $A$, maka

$$
P^{\mathrm{T}} A P=\left[\begin{array}{cc}
\lambda_{1} & 0 \\
0 & \lambda_{2}
\end{array}\right],
$$

dimana $\lambda_{1}$ dan $\lambda_{2}$ adalah nilai eigen dari A. Sehingga (7) dapat dituliskan kembali sebagai

$$
\begin{gathered}
{\left[\begin{array}{ll}
x^{\prime} & y^{\prime}
\end{array}\right]\left[\begin{array}{cc}
\lambda_{1} & 0 \\
0 & \lambda_{2}
\end{array}\right]\left[\begin{array}{l}
x^{\prime} \\
y^{\prime}
\end{array}\right]+} \\
{\left[\begin{array}{ll}
d & e
\end{array}\right]\left[\begin{array}{ll}
p_{11} & p_{12} \\
p_{21} & p_{22}
\end{array}\right]\left[\begin{array}{l}
x^{\prime} \\
y^{\prime}
\end{array}\right]+f=0}
\end{gathered}
$$

atau

$$
\lambda_{1} x^{\prime 2}+\lambda_{2} y^{\prime 2}+d^{\prime} x^{\prime}+e^{\prime} y^{\prime}+f=0(\cdots \cdots
$$

dimana $d^{\prime}=d p_{11}+e p_{21}$ dan $e^{\prime}=d p_{12}+$ $e p_{22}$. Persamaan (8) tidak memiliki suku hasilkali silang.

\section{Contoh :}

Gambarkan irisan kerucut dengan persamaan $5 x^{2}-4 x y+8 y^{2}-36=0$.

\section{Penyelesaian :}

Bentuk matriks dari

$$
5 x^{2}-4 x y+8 y^{2}-36=0
$$

adalah

$$
\mathbf{x}^{\mathrm{T}} A \mathbf{x}-36=0
$$

dengan

$$
\mathbf{x}=\left[\begin{array}{l}
x \\
y
\end{array}\right], \quad A=\left[\begin{array}{rr}
5 & -2 \\
-2 & 8
\end{array}\right] .
$$

Misalkan $\lambda$ adalah nilai eigen dari matriks simetris $A$. Maka

$$
\begin{gathered}
\operatorname{det}(\lambda I-A)=\operatorname{det}\left[\begin{array}{rr}
\lambda-5 & 2 \\
2 & \lambda-8
\end{array}\right]=\lambda^{2}- \\
13 \lambda+36=(\lambda-9)(\lambda-4)=0
\end{gathered}
$$

sehingga diperoleh nilai eigen dari $A$ adalah $\lambda=9$ dan $\lambda=4$.

Jika $\mathbf{x}$ vektor eigen yang sesuai nilai eigen $\lambda=9$, maka $A \mathbf{x}=9 \mathbf{x}$ atau

$$
\begin{aligned}
(9 I-A) \mathbf{x}=0 & \Leftrightarrow\left[\begin{array}{ll}
4 & 2 \\
2 & 1
\end{array}\right] \mathbf{x}=0 \\
& \Leftrightarrow\left[\begin{array}{ll}
1 & \frac{1}{2} \\
0 & 0
\end{array}\right]\left[\begin{array}{l}
x \\
y
\end{array}\right]=0, \\
& \Leftrightarrow x+1 / 2 y=0
\end{aligned}
$$$$
\mathbf{x}=\left[\begin{array}{l}
x \\
y
\end{array}\right]
$$

$=\left[\begin{array}{c}-\frac{1}{2} \\ 1\end{array}\right] t$, dengan $t$ parameter.

Jika $\mathbf{x}$ vektor eigen yang sesuai nilai eigen $\lambda=4$, maka $A \mathbf{x}=4 \mathbf{x}$ atau

$(4 I-A) \mathbf{x}=0 \Leftrightarrow\left[\begin{array}{rr}-1 & 2 \\ 2 & -4\end{array}\right] \mathbf{x}=0$ 


$$
\begin{aligned}
& \Leftrightarrow\left[\begin{array}{rr}
1 & -2 \\
0 & 0
\end{array}\right]\left[\begin{array}{l}
x \\
y
\end{array}\right] \mathbf{x}=0, \\
& \Leftrightarrow x-2 y=0 \\
\Leftrightarrow \quad & \mathbf{x}=\left[\begin{array}{l}
x \\
y
\end{array}\right]=\left[\begin{array}{l}
2 \\
1
\end{array}\right] s, \text { dengan } s
\end{aligned}
$$

parameter.

Sehingga diperoleh vektor-vektor pada basis ruang eigen,yaitu

$$
v_{1}=\left[\begin{array}{c}
-\frac{1}{2} \\
1
\end{array}\right] \text { dan } v_{2}=\left[\begin{array}{l}
2 \\
1
\end{array}\right] .
$$

Selanjutnya akan dilakukan proses GramSchmidt terhadap vektor-vektor tersebut untuk mendapatkan matriks $P$ yang mendiagonalisasi $A$ secara ortogonal. Misalkan vektor $p_{1}$ dan $p_{2}$ adalah hasil dari proses tersebut, maka

$$
\begin{gathered}
p_{1}=\frac{v_{1}}{\left\|v_{1}\right\|}=\frac{1}{\sqrt{\left(-\frac{1}{2}\right)^{2}+1^{2}}}\left[\begin{array}{c}
-\frac{1}{2} \\
1
\end{array}\right] \\
=\frac{2}{\sqrt{5}}\left[\begin{array}{c}
-\frac{1}{2} \\
1
\end{array}\right]=\left[\begin{array}{c}
-\frac{1}{\sqrt{5}} \\
\frac{2}{\sqrt{5}}
\end{array}\right] \\
p_{2}=\frac{v_{2}-\left\langle v_{2}, p_{1}\right\rangle p_{1}}{\left\|v_{2}-\left\langle v_{2}, p_{1}\right\rangle p_{1}\right\|} \\
=\frac{\left[\begin{array}{l}
2 \\
1
\end{array}\right]-\left\langle\left[\begin{array}{l}
2 \\
1
\end{array}\right],\left[\begin{array}{l}
-\frac{1}{\sqrt{5}} \\
\frac{2}{\sqrt{5}}
\end{array}\right]\right\rangle\left[\begin{array}{l}
-\frac{1}{\sqrt{5}} \\
\frac{2}{\sqrt{5}}
\end{array}\right]}{\left\|\left[\begin{array}{l}
2 \\
1
\end{array}\right]-\left\langle\left[\begin{array}{l}
2 \\
1
\end{array}\right],\left[\begin{array}{l}
-\frac{1}{\sqrt{5}} \\
\frac{2}{\sqrt{5}}
\end{array}\right]\right\rangle\left[\begin{array}{c}
-\frac{1}{\sqrt{5}} \\
\frac{2}{\sqrt{5}}
\end{array}\right]\right\|} \\
=\frac{\left[\begin{array}{l}
2 \\
1
\end{array}\right]}{\sqrt{5}}=\left[\begin{array}{l}
\frac{2}{\sqrt{5}} \\
\frac{1}{\sqrt{5}}
\end{array}\right],
\end{gathered}
$$

dimana

$$
P=\left[\begin{array}{ll}
p_{2} & p_{1}
\end{array}\right]=\left[\begin{array}{cc}
\frac{2}{\sqrt{5}} & -\frac{1}{\sqrt{5}} \\
\frac{1}{\sqrt{5}} & \frac{2}{\sqrt{5}}
\end{array}\right] .
$$

Susunan kolom dari $P$ disesuaikan agar $\operatorname{det}(P)=1$. Karena itu transformasi koordinat ortogonal

$$
\mathbf{x}=P \mathbf{x}^{\prime}
$$

adalah sebuah rotasi. Dengan menerapkan persamaan (7) diperoleh

$$
\left[\begin{array}{ll}
x^{\prime} & y^{\prime}
\end{array}\right]\left[\begin{array}{ll}
4 & 0 \\
0 & 9
\end{array}\right]\left[\begin{array}{l}
x^{\prime} \\
y^{\prime}
\end{array}\right]-36=0
$$

atau

$$
4 x^{\prime 2}+9 y^{\prime 2}-36=0 \text { atau } \frac{x^{\prime 2}}{9}+\frac{y^{2}}{4}=1,
$$

yang merupakan persamaan elips. Vektor $p 1$ dan $p 2$ berturut-turut adalah vektor pada sumbu koordinat $x^{\prime} y^{\prime}$. Sehingga diperoleh gambar irisan kerucut pada Gambar 5.

Jika irisan kerucut yang ditransformasikan tidak berpusat di titik asal $(0,0)$, kita cukup melakukan langkah rotasi di atas. Selanjutnya kita dapat menerapkan cara yang biasa ketika menggambarkan suatu irisan kerucut yang berpusat di titik $(a, b)$, atau kita dapat melanjutkan dengan langkah berikutnya yaitu melakukan translasi terhadap sistem koordinat $x^{\prime} y^{\prime}$.

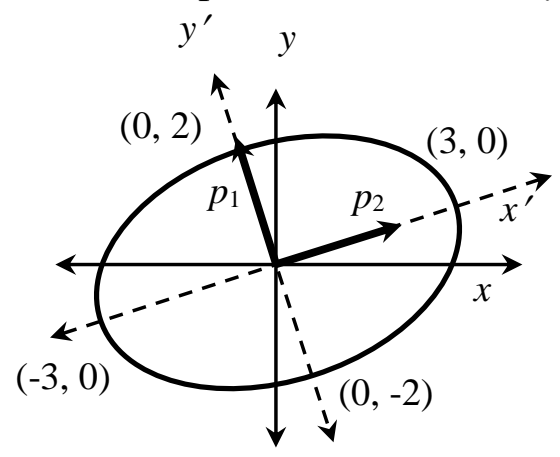

Gambar 5

\section{KESIMPULAN DAN SARAN}

Berdasarkan pembahasan diatas dapat ditarik beberapa kesimpulan, yaitu:

1. Setiap persamaan irisan kerucut memiliki suatu bentuk kuadratik yang dapat ditransformasikan menjadi bentuk kuadratik yang tidak memiliki suku-suku perkalian silang dengan melakukan proses diagonalisasi matriks.

2. Suatu irisan kerucut bentuk kanonik (standar) tidak memiliki suku-suku perkalian silang. 
3. Suatu irisan kerucut yang memiliki suku perkalian silang mengindikasikan bahwa irisan kerucut tersebut diputar sehingga keluar dari posisi standarnya.

Berdasarkan uraian di atas hingga kesimpulan dapat dipahami bahwa setiap bentuk kuadratik dapat ditransformasikan menjadi bentuk kuadratik yang lebih sederhana. Suatu irisan kerucut memuat bentuk kuadratik dengan dua variabel. Begitu juga dengan permukaan kuadrik memiliki bentuk kuadratik yang diasosiasikan dengan tiga variabel. Karena itu bagi peminat aljabar dan geometri dapat pula melanjutkannya pada permukaan kuadrik.

\section{DAFTAR PUSTAKA}

Anton, Howard., 1994, Elementary Linear Algebra : Aplications Version, John Wiley \& Sons, New York.

Eves, Howard, 1972, A Survey of Geometry, Allyn and Bacon Wesley, London.

Moise, Edwin E., 1990, Elementary Geometry, Addison - Wesley, New York.

Morrill, W. K., 1964, Analytic Geometry, Second edition, International Textbook Company, Pennsylvania.

Wallace, Edward C., 1992, Roads to Geometry, Prentice Hall, New Jersey. 